\title{
Study on Interface Reaction of BN-Al Composite Materials
}

\author{
Chao Wang ${ }^{1 *}$, Mengge Dong2 ${ }^{2}$ Lu Zhang ${ }^{3}$, Xiaozhou $\mathrm{Cao}^{2 *}$, and Xiangxin Xue ${ }^{2^{\star}}$ \\ 1Department of Mechanical Engineering, The University of Texas at Dallas, Richardson, TX, 75080, USA \\ 2School of Metallurgy, Northeastern University, Shenyang, Liaoning, 110819, China \\ ${ }^{3}$ School of Energy and Environment, Anhui University of Technology, Ma'anshan, 243002, China
}

Chao Wang, and Mengge Dong made an equal contribution.

${ }^{*}$ Corresponding author.

E-mail: wang.chao@utdallas.edu, caoxz@smm.neu.edu.cn, xuexx@mail.neu.edu.cn

\begin{abstract}
Ceramic-metal composite materials prepared by the metal infiltration process have become the topic of intense research. The interface reaction between ceramic and metal has an important impact on the mechanical properties of composite materials. This article, for the first time, studies the interface reaction between BN and Al. Scanning electron microscopy (SEM) and transmission electron microscopy (TEM) were both employed to study interface reaction. Studies have shown that there is an intermediate transition interface between metal and ceramic. The interface reaction between $\mathrm{Al}$ and BN produces AIN, and there is no close connection among AIN particles. The grain size of AIN is about 1 $2 \mu \mathrm{m}$. The rate order is: Al element $>$ B element $>\mathrm{N}$ element.
\end{abstract}

Keywords: Metal infiltration, BN-Al, Interface reaction, Composite material, TEM

\section{Introduction}

Ceramic materials are a class of inorganic, non-metallic materials made by melting and hightemperature sintering (1-3). It has the advantages of having a high melting point $(4,5)$, substantial hardness $(6-8)$, high wear resistance $(9,10)$, and oxidation resistance (11). The chemical bonds of ceramic materials are mostly ionic and covalent bonds. Consequently, its strength, hardness, elastic modulus, abrasion resistance, corrosion resistance, and heat resistance are superior to metals (12$15)$.

Composite materials are also called cermets. It is a new type of material that can enhance transportation capacity and energy conversion (16-19). Cermet combines the advantages of the main components of ceramics and metals, including the hardness of ceramics, high temperature stability, and the workability and ductility of metals (20-22).

The preparation methods of cermet composite materials include powder metallurgy, thermal spraying, vapor deposition, chemical deposition, self-propagating, sol-gel, and metal infiltration (23-28). The metal infiltration method first uses the capillary force of the porous ceramic preform, using powder sintering to suck molten metal into the ceramic preform. The method is simple and 
easy to operate, and the composite material has good uniformity (29). In the metal infiltration process carried out at high temperature, the interface between the metal and the ceramic material tends to have a fierce interfacial reaction, which destroys the mechanical properties of the composite material (30). Therefore, the research on the interface and the interface reaction becomes particularly essential.

Boron nitride has good heat resistance, thermal stability, thermal conductivity, and hightemperature dielectric strength (31-33). It is an ideal heat dissipation material and high-temperature insulating ceramic material. Its boron content reaches $43.6 \%$, which is very promising as a neutron shielding material. In previous studies, in an effort to improve its toughness and other defects, the Al-BN composite was prepared at 1100 degrees using a metal infiltration process, and to improve the interface wettability between $\mathrm{BN}$ and $\mathrm{Al}$, different contents of $\mathrm{TiB}_{2}$ are added to $\mathrm{BN}$ (31).

This article discusses the BN-Al interface and analyzes the microstructure of the interface reaction.

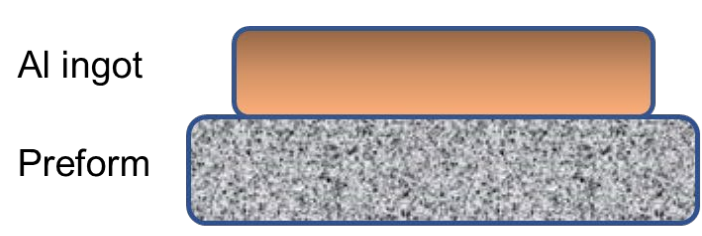

Before infiltration

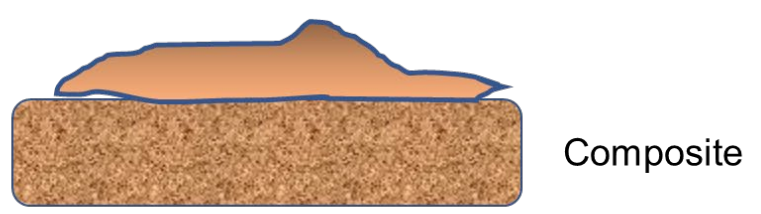

After infiltration

Figure 1 Schematic diagram of melt infiltration

\section{Materials and Methodology}

The $\mathrm{BN}-\mathrm{Al}$ composite material with $\mathrm{TiB}_{2}$ added is prepared by vacuum infiltration. The amount of $\mathrm{TiB}_{2}$ added is $20 \%$, an approach different from those used in previous research (16, 31). The details of the fresh interface were investigated using a scanning electron microscope (SEM, ULTRA PLUS). In addition, energy dispersive spectroscopy (EDS) was used for composition analysis. Finally, a transmission electron microscope (TEM, TECNAI G220) was used to observe the interface between metal and composite material of BN-based boron-containing composite material, and it was also used to perform energy spectrum (EDS) analysis of component phase.

\section{Results and Discussion}

Figure 2 shows the contact interface between the metal and the preform of the BN-based boron-containing composite, prepared by the metal infiltration method. It shows that the contact interface is divided into three layers, and the boundary between the layers is clear. The thickness of the intermediate layer is about $100 \mu \mathrm{m}$. The first layer has pores, and the third layer has no pores, indicating the level of metal infiltration, and the composite material prepared through the use of this method is very compact. 


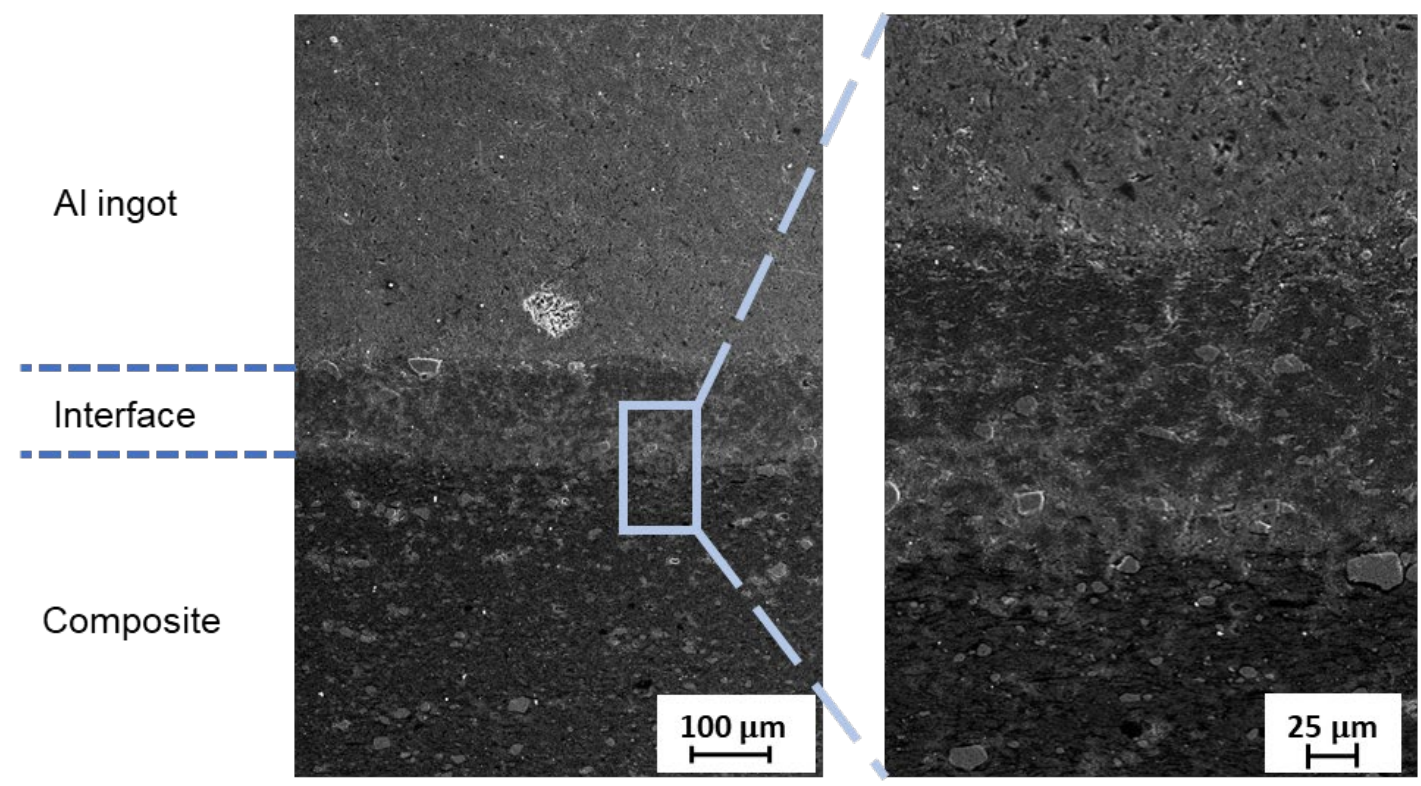

Figure 2 Interface image of melt infiltration

Figure 3 is a scaled-up photo of the metal infiltration interface and energy spectrum analysis. The analysis shows that there is $\mathrm{AlN}$ in the second layer, and $\mathrm{AlN}, \mathrm{TiB}_{2}$ and $\mathrm{AlB}_{12}$ in the third layer. During the metal infiltration process, elemental aluminum is found in the first layer and in the third layer. The boundary between layers is clear, with no elemental aluminum. It can be seen from the morphology between the three layers that the color of the first layer is relatively consistent, and no obvious abnormal substances are present. The micro morphology of the third layer is basically the same as that in Figure 2. In contrast, the second layer is a transition zone between the first layer and the third layers, where the elemental metal $\mathrm{Al}$ is mixed with the $\mathrm{BN}$ based composite material, and $\mathrm{Al}$ is slightly present in the third layer. 

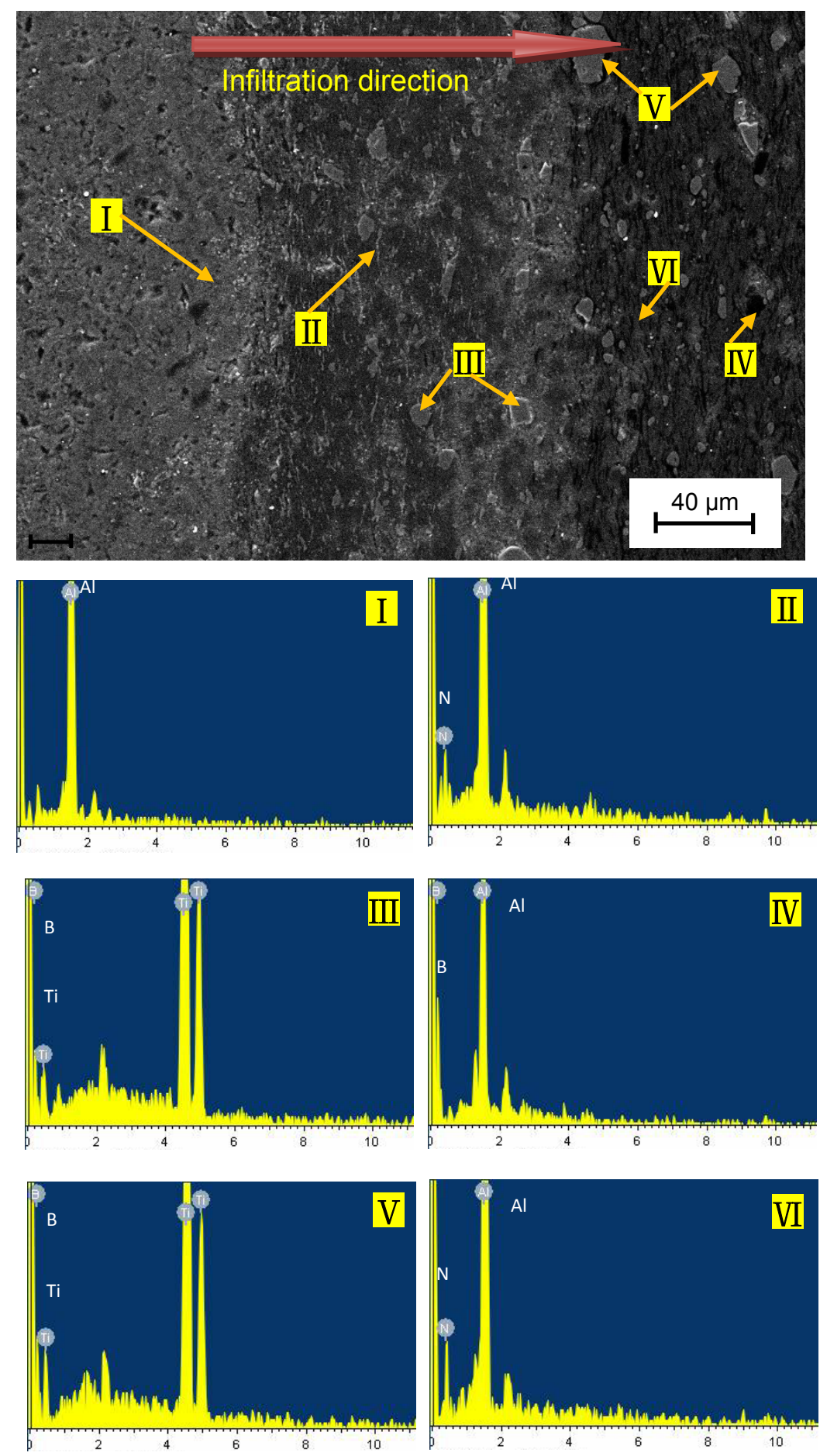

Figure 3 Interface image of melt infiltration and EDS analysis

Figure 4 is a scan photo of the energy spectrum of the metal infiltration interface. The elemental analysis line scan shows that the Al element diffuses significantly in the direction of metal infiltration, the peak of $\mathrm{Al}$ element tends to weaken along the direction of metal infiltration, while the Ti element, $\mathrm{N}$ element, and B element are slightly present in the first layer. Additionally, 
there are relatively more B elements, and the element distribution between layers is extremely obvious. It can also be seen from the Figure 4 that there are B and $\mathrm{N}$ elements in the $\mathrm{Al}$ melt. Their presence shows that the $\mathrm{B}$ and $\mathrm{N}$ elements diffuse into the $\mathrm{Al}$ melt, and the order of the diffusion rate is as follows: The Al element, B element, and $\mathrm{N}$ element are consistent with the information on the mutual diffusion of $\mathrm{Al}$ and $\mathrm{BN}$ found in the current research literature. In contrast, hardly any diffusion occurs with the Ti element.

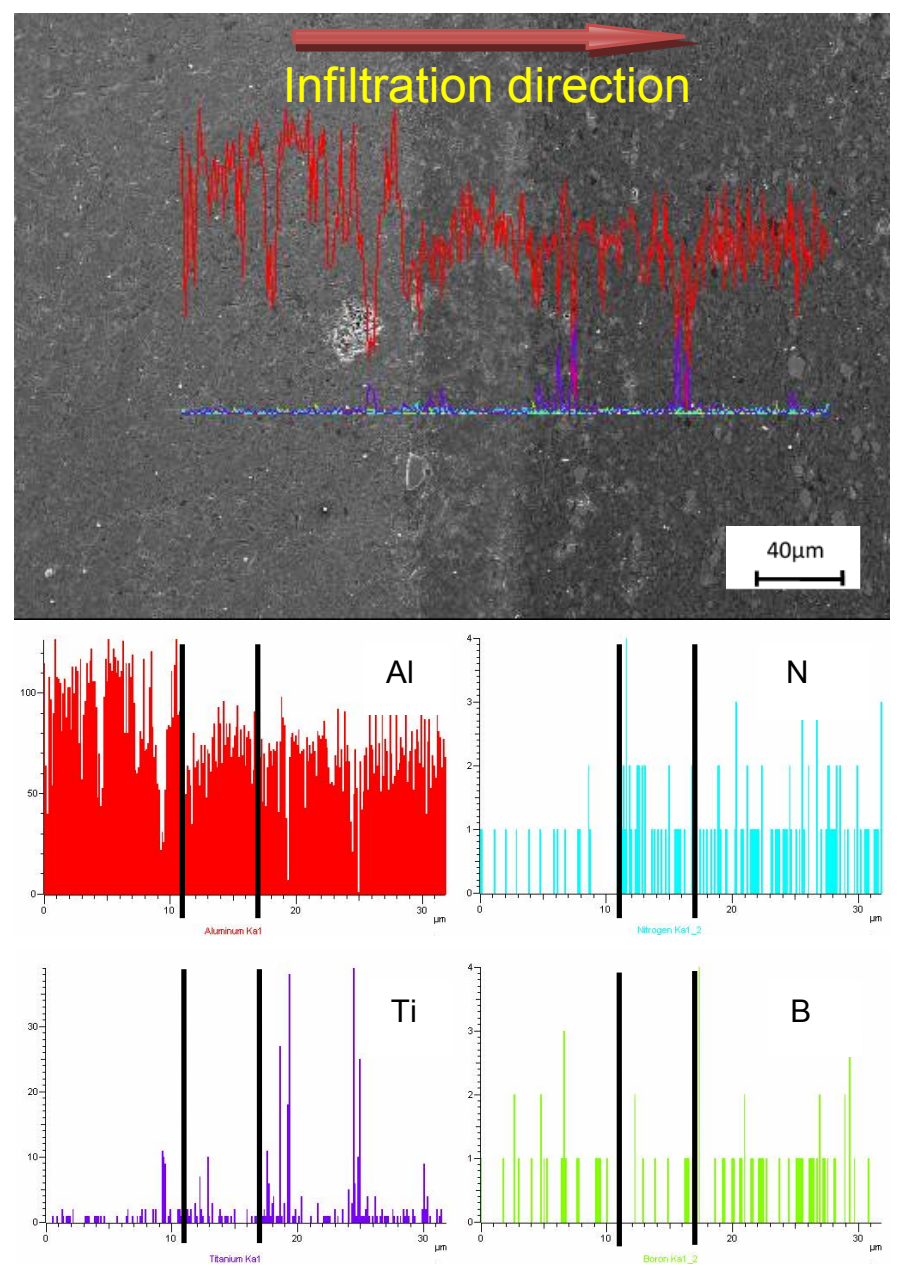

Figure 4 EDS line scanning of melt infiltration interface

The interface reaction between $\mathrm{BN}$ and $\mathrm{Al}$ is as follows:

$$
\begin{gathered}
\mathrm{BN}(\mathrm{s})+\mathrm{Al}(\mathrm{l}) \rightarrow \mathrm{AlN}(\mathrm{s})+\mathrm{B}(\mathrm{Al})+\alpha \mathrm{AlB}_{12}(\mathrm{~s}) \\
\left(\Delta G^{\theta}=-1148.2+0.22 T, 273 K<T<933 K\right) \\
\left(\Delta G^{\theta}=-1320.1+0.4 T, 933 K<T<1473 K\right)
\end{gathered}
$$

The metal impregnation temperature in this test is $1373 \mathrm{~K}\left(1100^{\circ} \mathrm{C}\right)$, and its standard Gibbs free energy is $\Delta G^{\theta}=-770.9 \mathrm{~kJ} \cdot \mathrm{mol}^{-1}$, indicating that the reaction equation (1) can occur at this temperature. 


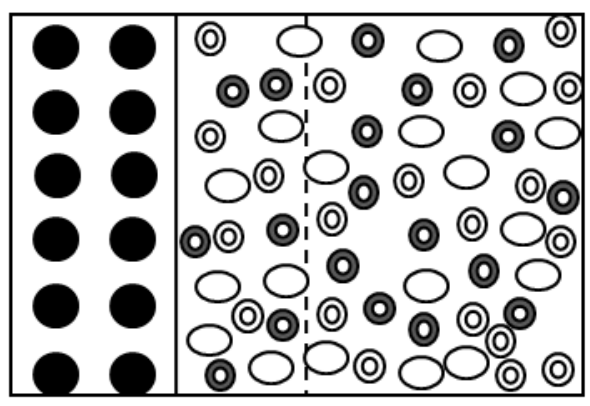

Al atom $\mathrm{Ti}$ atom

Before infiltration

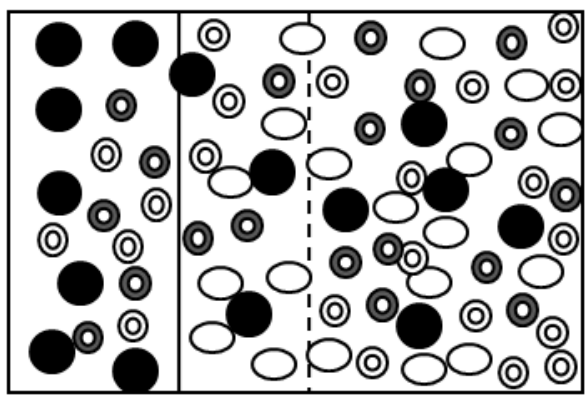

(-) B atom () $\mathrm{N}$ atom

After infiltration

Figure 5 Reaction diffuse model of melt infiltration interface

Figure 5 shows the reaction diffusion model of the metal infiltration interface drawn by simulating the actual diffusion phenomenon. Among them, the infiltration effect of Al into the preform is significant, and the basic position of $\mathrm{TiB}_{2}$ remains unchanged. In addition to the interface reaction with $\mathrm{Al}, \mathrm{BN}$ also diffuses into the $\mathrm{Al}$ melt.
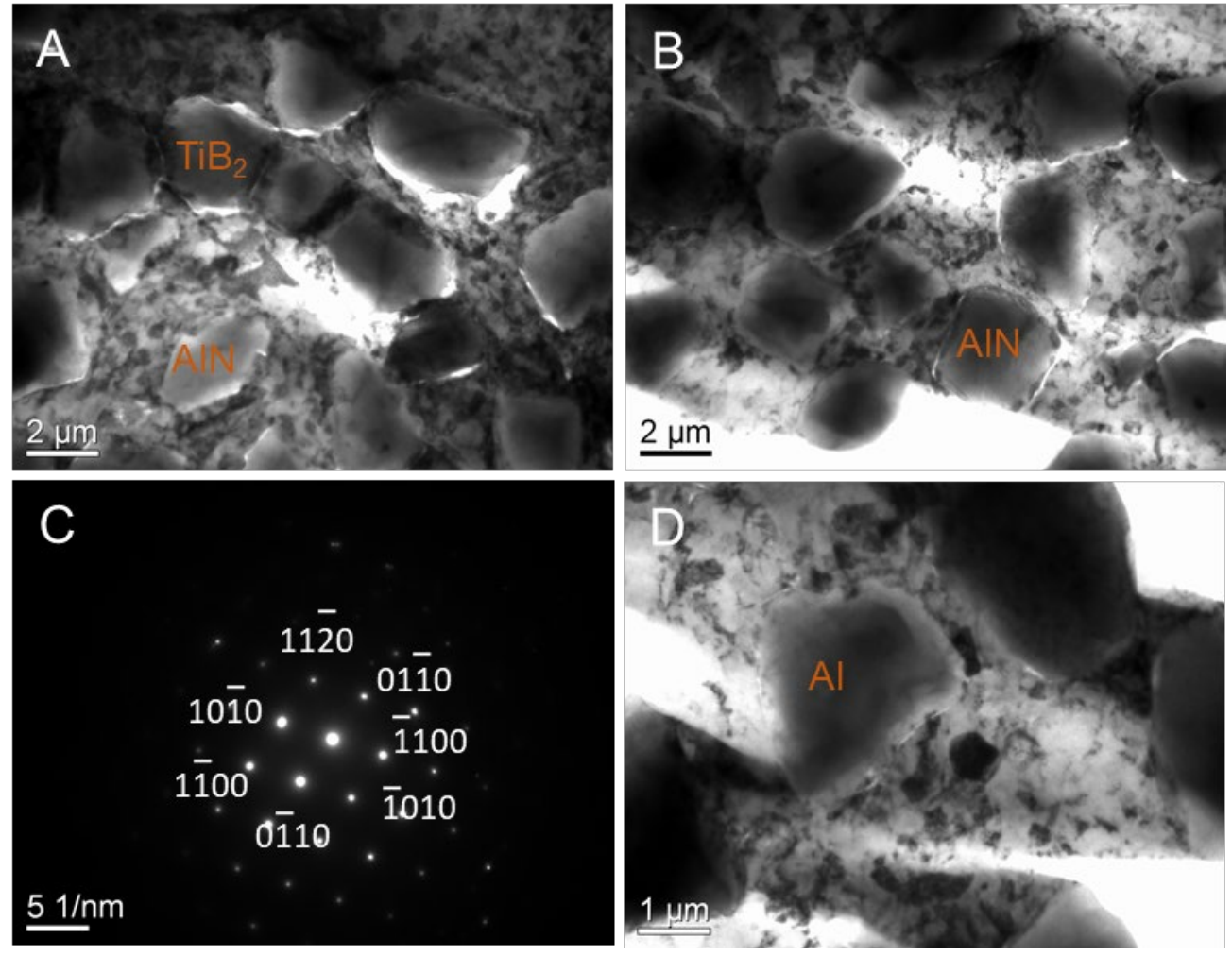

Figure 6 TEM images of BN matrix composites: (A) TEM morphology; (B) TEM morphology; (C) Diffraction pattern of AIN; (D) TEM morphology.

TEM is used to observe the microscopic morphology of BN-based, boron-containing composite materials and identify their basic phase composition. Figure 6 (a), (b) and (d) are TEM pictures of BN-based, boron-containing composite materials, clearly showing that the $\mathrm{TiB}_{2}$ 
sintering phenomenon is obvious, the $\mathrm{TiB}_{2}$ crystal boundary is clear, the $\mathrm{AlN}$ produced is relatively independent, and there is no tight connection between the particles. The grain size of the AlN is about $1 \sim 2 \mu \mathrm{m}$, which is the same as Lee indicated about the BN/Al interface. Figure 6(c) shows the diffraction pattern of AlN. Through analysis of the spots, it is apparent that it is the diffraction pattern of AlN, and the crystal ribbon axis is [0001].

\section{Summary}

This paper studies the interface reaction between $\mathrm{BN}$ and $\mathrm{Al}$. It can be seen from the interface morphology of the metal infiltration that there is an obvious delamination. The infiltration effect of $\mathrm{Al}$ into the preform is significant, the basic position of $\mathrm{TiB}_{2}$ remains unchanged, and $\mathrm{BN}$, in addition to the interface reaction with $\mathrm{Al}$, also diffuses into the $\mathrm{Al}$ melt.

\section{Notes}

The authors declare that they have no competing financial interests.

\section{Acknowledgements}

This work was supported by the fundamental, scientific-research business resources of the central universities (award \# N10060200).

\section{Notes}

The authors declare no competing financial interest.

\section{Acknowledgements}

This work was supported by Fundamental scientific research business expenses of central universities (award \# N10060200).

\section{References}

1. Luo X, et al. (2009) Influence of metallic additives on densification behaviour of hot-pressed $\mathrm{TiB}_{2}$. Light Metals:1151-1155.

2. Chao W, et al. (2013) A New Method of Fabricating AIN-TiB 2 Composite Ceramics. Materials and manufacturing processes 28(8):953-956.

3. Carter CB \& Norton MG (2007) Ceramic materials: science and engineering (Springer).

4. Cao X, et al. (2013) Effect of Ni addition on pressureless sintering of tungsten diboride. International Journal of Refractory Metals and Hard Materials 41:597-602.

5. Cao XZ, et al. (2011) High temperature electrochemical synthesis of tungsten boride from molten salt. Advanced Materials Research, (Trans Tech Publ), pp 463-466.

6. Wang $C$, et al. (2021) Preparation of $A_{1 B} B_{12}$ Powder by Self-Propagating High-Temperature Synthesis (SHS). (ChemRxiv).

7. Wang $C$, et al. (2014) Elementary research on preparation of $\mathrm{AlB}_{12}$ powder by self-propagating high-temperature synthesis (SHS). Materials Science Forum, (Trans Tech Publ), pp 365-369.

8. Rahaman MN (2000) Ceramic processing. Kirk-Othmer Encyclopedia of Chemical Technology:198. 
9. Qi D, et al. (2019) Preparation and Erosion Performance for Co-continuous Phase Composites of $\mathrm{Si}_{3} \mathrm{~N}_{4} / 1 \mathrm{Cr} 18 \mathrm{Ni9Ti}$. Chinese Journal of Materials Research 33(1):34-42.

10. Medvedovski E (2001) Wear-resistant engineering ceramics. Wear 249(9):821-828.

11. Luo C, Jiao T, Gu J, Tang Y, \& Kong J (2018) Graphene shield by SiBCN ceramic: a promising hightemperature electromagnetic wave-absorbing material with oxidation resistance. ACS applied materials \& interfaces 10(45):39307-39318.

12. Mohammadreza M, et al. (2020) 3-Dimensional Printing of Ceramics Through" Carving" a Gel and" Filling In" the Precursor Polymer. ACS applied materials \& interfaces:31984-31991.

13. WANG C, et al. (2013) Research Progress on Aluminum-Boron Compounds (Al-B) and Its Composite Materials. Bulletin of the Chinese Ceramic Society: 10.

14. Xiao-Zhou C, Chao W, Xiang-Xin X, \& He Y (2014) Preparation of tungsten boride ceramic by pressureless sintering. JOURNAL OF INORGANIC MATERIALS 29(5):498-502.

15. Mukerji J (1993) Ceramic Matrix Composites. Defence Science Journal 43(4):385.

16. Chao W, Xiangxin X, Xiaozhou C, He Y, \& Gongjin C (2013) The effect of Ti addition on the microstructure and fracture toughness of BN-Al composite materials synthesized by vacuum infiltration. Archives of Metallurgy and Materials 58(2):509--512.

17. Wang C, et al. (2021) Research on Thermal Neutron Shielding Performance of $\mathrm{TiB}_{2}$-Al Composite Materials. (ChemRxiv).

18. Xiaozhou C, Chao W, Xiangxin X, \& Gongjin C (2015) Effect of ti addition on the residual aluminium content and mechanical properties of the $\mathrm{B}_{4} \mathrm{C}$-al composites produced by vacuum infiltration. Archives of Metallurgy and Materials 60.

19. Levin L, Frage N, \& Dariel M (2000) A novel approach for the preparation of $\mathrm{B}_{4} \mathrm{C}$-based cermets. International Journal of Refractory Metals and Hard Materials 18(2-3):131-135.

20. Wang C, et al. (2021) Theoretical Calculation of Self-Propagating High-Temperature Synthesis (SHS) Preparation of AlB 12 . (ChemRxiv).

21. Wang C, Zhang J, Xue XX, \& Cao XZ (2013) Fabrication B-Ni-Al Shielding Materials by Vacuum Metal Infiltration. Advanced Materials Research, (Trans Tech Publ), pp 410-413.

22. Aramian A, Razavi SMJ, Sadeghian Z, \& Berto F (2020) A review of additive manufacturing of cermets. Additive Manufacturing 33:101130.

23. Cao X, et al. (2020) Electrochemical Behavior and Electrodeposition of Sn Coating from Choline Chloride-Urea Deep Eutectic Solvents. Coatings 10(12):1154.

24. Hu X-w, et al. (2007) $\mathrm{Nd}_{2} \mathrm{O}_{3}$ Solubility in $\mathrm{NdF}_{3}-\mathrm{LiF}_{-}-\mathrm{Nd}_{2} \mathrm{O}_{3}$ Melts. Proceedings of.

25. Wang C, Hossain Bhuiyan ME, Moreno S, \& Minary-Jolandan M (2020) Direct-Write Printing Copper-Nickel (Cu/Ni) Alloy with Controlled Composition from a Single Electrolyte Using CoElectrodeposition. ACS applied materials \& interfaces 12(16):18683-18691.

26. Dong $\mathrm{M}$, et al. (2016) A novel comprehensive utilization of vanadium slag: As gamma ray shielding material. Journal of hazardous materials 318:751-757.

27. Marple B, Voyer J, Bisson J-F, \& Moreau C (2001) Thermal spraying of nanostructured cermet coatings. Journal of Materials Processing Technology 117(3):418-423.

28. Yang W, et al. (2017) Structure and properties of PVD TiAIN and TiAIN/CrAIN coated Ti (C, N)based cermets. Ceramics International 43(2):1911-1915.

29. Chapman T, Niesz D, Fox R, \& Fawcett T (1999) Wear-resistant aluminum-boron-carbide cermets for automotive brake applications. Wear 236(1-2):81-87.

30. Delanoë A, Bacia M, Pauty E, Lay S, \& Allibert C (2004) Cr-rich layer at the WC/Co interface in Crdoped WC-Co cermets: segregation or metastable carbide? Journal of Crystal growth 270(12):219-227. 
31. Wang C, Xue X-X, Cao X-Z, \& Yang H (2012) Effect of BN addition on mechanical properties and microstructure of $\mathrm{TiB}_{2}-\mathrm{Al}$ composites. Journal of Northeastern University (Natural Science) 33(9):1290.

32. Tao W, et al. (2009) Finite element analysis of thermo-electric coupled field in 400kA large-scale aluminum reduction cell. 2009 World Non-Grid-Connected Wind Power and Energy Conference, (IEEE), pp 1-4.

33. Lee K, et al. (2002) Tensile properties and microstructures of Al composite reinforced with BN particles. Composites Part A: Applied Science and Manufacturing 33(5):709-715.

1. Luo X, et al. (2009) Influence of metallic additives on densification behaviour of hot-pressed TiB2. Light Metals:1151-1155.

2. Chao W, et al. (2013) A New Method of Fabricating AlN-TiB2 Composite Ceramics. Materials and manufacturing processes 28(8):953-956.

3. Carter CB \& Norton MG (2007) Ceramic materials: science and engineering (Springer).

4. Cao X, et al. (2013) Effect of Ni addition on pressureless sintering of tungsten diboride.

International Journal of Refractory Metals and Hard Materials 41:597-602.

5. Cao XZ, et al. (2011) High temperature electrochemical synthesis of tungsten boride from molten salt. Advanced Materials Research, (Trans Tech Publ), pp 463-466.

6. Wang C, et al. (2021) Preparation of AlB12 Powder by Self-Propagating High-Temperature Synthesis (SHS). (ChemRxiv).

7. Wang C, et al. (2014) Elementary research on preparation of AlB12 powder by self-propagating high-temperature synthesis (SHS). Materials Science Forum, (Trans Tech Publ), pp 365-369.

8. Rahaman MN (2000) Ceramic processing. Kirk-Othmer Encyclopedia of Chemical Technology:198.

9. Qi D, et al. (2019) Preparation and Erosion Performance for Co-continuous Phase Composites of Si3N4/1Cr18Ni9Ti. Chinese Journal of Materials Research 33(1):34-42.

10. Medvedovski E (2001) Wear-resistant engineering ceramics. Wear 249(9):821-828.

11. Luo C, Jiao T, Gu J, Tang Y, \& Kong J (2018) Graphene shield by SiBCN ceramic: a promising high-temperature electromagnetic wave-absorbing material with oxidation resistance. $A C S$ applied materials \& interfaces 10(45):39307-39318.

12. Mohammadreza M, et al. (2020) 3-Dimensional Printing of Ceramics Through" Carving" a Gel and" Filling In" the Precursor Polymer. ACS applied materials \& interfaces.

13. WANG C, et al. (2013) Research Progress on Aluminum-Boron Compounds (Al-B) and Its Composite Materials. Bulletin of the Chinese Ceramic Society: 10.

14. Xiao-Zhou C, Chao W, Xiang-Xin X, \& He Y (2014) Preparation of tungsten boride ceramic by pressureless sintering. JOURNAL OF INORGANIC MATERIALS 29(5):498-502.

15. Mukerji J (1993) Ceramic Matrix Composites. Defence Science Journal 43(4):385.

16. Chao W, Xiangxin X, Xiaozhou C, He Y, \& Gongjin C (2013) The effect of Ti addition on the microstructure and fracture toughness of $\mathrm{BN}-\mathrm{Al}$ composite materials synthesized by vacuum infiltration. Archives of Metallurgy and Materials 58(2):509--512.

17. Wang C, et al. (2021) Research on Thermal Neutron Shielding Performance of TiB2-A1 Composite Materials. (ChemRxiv).

18. Xiaozhou C, Chao W, Xiangxin X, \& Gongjin C (2015) Effect of ti addition on the residual aluminium content and mechanical properties of the $\mathrm{B} 4 \mathrm{C}$-al composites produced by vacuum infiltration. Archives of Metallurgy and Materials 60.

19. Levin L, Frage N, \& Dariel M (2000) A novel approach for the preparation of B4C-based cermets. International Journal of Refractory Metals and Hard Materials 18(2-3):131-135.

20. Wang C, et al. (2021) Theoretical Calculation of Self-Propagating High-Temperature Synthesis (SHS) Preparation of AlB12. (ChemRxiv). 
21. Wang C, Zhang J, Xue XX, \& Cao XZ (2013) Fabrication B-Ni-Al Shielding Materials by Vacuum Metal Infiltration. Advanced Materials Research, (Trans Tech Publ), pp 410-413.

22. Aramian A, Razavi SMJ, Sadeghian Z, \& Berto F (2020) A review of additive manufacturing of cermets. Additive Manufacturing 33:101130.

23. Cao X, et al. (2020) Electrochemical Behavior and Electrodeposition of Sn Coating from Choline Chloride-Urea Deep Eutectic Solvents. Coatings 10(12):1154.

24. $\mathrm{Hu} \mathrm{X}-\mathrm{w}$, et al. (2007) Nd2O3 Solubility in NdF3-LiF-Nd2O3 Melts. Proceedings of.

25. Wang C, Hossain Bhuiyan ME, Moreno S, \& Minary-Jolandan M (2020) Direct-Write Printing Copper-Nickel (Cu/Ni) Alloy with Controlled Composition from a Single Electrolyte Using CoElectrodeposition. ACS applied materials \& interfaces 12(16):18683-18691.

26. Dong M, et al. (2016) A novel comprehensive utilization of vanadium slag: As gamma ray shielding material. Journal of hazardous materials 318:751-757.

27. Marple B, Voyer J, Bisson J-F, \& Moreau C (2001) Thermal spraying of nanostructured cermet coatings. Journal of Materials Processing Technology 117(3):418-423.

28. Yang W, et al. (2017) Structure and properties of PVD TiAlN and TiAlN/CrAlN coated Ti (C, N)-based cermets. Ceramics International 43(2):1911-1915.

29. Chapman T, Niesz D, Fox R, \& Fawcett T (1999) Wear-resistant aluminum-boron-carbide cermets for automotive brake applications. Wear 236(1-2):81-87.

30. Delanoë A, Bacia M, Pauty E, Lay S, \& Allibert C (2004) Cr-rich layer at the WC/Co interface in Cr-doped WC-Co cermets: segregation or metastable carbide? Journal of Crystal growth 270(12):219-227.

31. Wang C, Xue X-X, Cao X-Z, \& Yang H (2012) Effect of BN addition on mechanical properties and microstructure of TiB2-Al composites. Journal of Northeastern University (Natural Science) 33(9): 1290.

32. Tao W, et al. (2009) Finite element analysis of thermo-electric coupled field in 400kA large-scale aluminum reduction cell. 2009 World Non-Grid-Connected Wind Power and Energy Conference, (IEEE), pp 1-4.

33. Lee K, et al. (2002) Tensile properties and microstructures of Al composite reinforced with BN particles. Composites Part A: Applied Science and Manufacturing 33(5):709-715. 